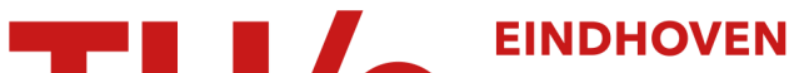

\section{Configuring collective digital-technology usage in dynamic and complex design practices}

Citation for published version (APA):

Verstegen, L., Houkes, W., \& Reymen, I. (2019). Configuring collective digital-technology usage in dynamic and complex design practices. Research Policy, 48(8), [103696]. https://doi.org/10.1016/j.respol.2018.10.020

\section{Document license:}

TAVERNE

DOI:

10.1016/j.respol.2018.10.020

Document status and date:

Published: 01/10/2019

\section{Document Version:}

Publisher's PDF, also known as Version of Record (includes final page, issue and volume numbers)

\section{Please check the document version of this publication:}

- A submitted manuscript is the version of the article upon submission and before peer-review. There can be important differences between the submitted version and the official published version of record. People interested in the research are advised to contact the author for the final version of the publication, or visit the $\mathrm{DOI}$ to the publisher's website.

- The final author version and the galley proof are versions of the publication after peer review.

- The final published version features the final layout of the paper including the volume, issue and page numbers.

Link to publication

\section{General rights}

Copyright and moral rights for the publications made accessible in the public portal are retained by the authors and/or other copyright owners and it is a condition of accessing publications that users recognise and abide by the legal requirements associated with these rights.

- Users may download and print one copy of any publication from the public portal for the purpose of private study or research.

- You may not further distribute the material or use it for any profit-making activity or commercial gain

- You may freely distribute the URL identifying the publication in the public portal.

If the publication is distributed under the terms of Article $25 \mathrm{fa}$ of the Dutch Copyright Act, indicated by the "Taverne" license above, please follow below link for the End User Agreement:

www.tue.nl/taverne

Take down policy

If you believe that this document breaches copyright please contact us at:

openaccess@tue.nl

providing details and we will investigate your claim. 


\title{
Configuring collective digital-technology usage in dynamic and complex design practices
}

\author{
Luuk Verstegen*, Wybo Houkes, Isabelle Reymen \\ Department of Industrial Engineering \& Innovation Sciences, Eindhoven University of Technology, Rondom 70, 5612 AP Eindhoven, the Netherlands
}

\section{A R T I C L E I N F O}

\section{Keywords:}

Configurational usage

Digital innovation

Organizing technology

Collective affordance

Architectural practice

Building information model (BIM)

\begin{abstract}
A B S T R A C T
Digital-technology usage in dynamic and complex work practices is a core phenomenon in innovation research. There are, however, few detailed analyses of how people organize the use of digital tools in their work practices. We aim to offer more insight into how individual actors use digital technology, how these actors organize its use in collectives, and how they organize their work with that of other actors in order to realize collective-level goals. We implemented a qualitative research design, based on interviews in architectural firms complemented with observations and archival data. By analyzing interactions of multiple individual actors with digital technology, we found that actors organize usage in collectives through activities that we call configuring-in-use and reflecting; and that they combine these two organizational activities in order to realize collective-level goals. We identify the combination of these organizational activities as configurational usage. We contribute to literature on the usage of pervasive digital technology by providing a detailed empirical investigation of organized usage of digital technology. Furthermore, we refine the conceptualization of configurational usage, improving understanding of core processes of digital innovation.
\end{abstract}

\section{Introduction}

Digital technologies and tools pervade modern business and are implemented in a wide variety of firms (Yoo et al., 2012). Usage of digital technologies has had a major impact on innovation processes, i.e., has redefined how products and services are created (Nambisan et al., 2017). In some cases, such as the replacement of chemical analogue photography by digital technologies in the photography industry, digital-technology usage has completely reconfigured industries (Benner and Tushman, 2002).

Digital-technology usage is a core phenomenon studied in innovation research (Burton-Jones and Gallivan, 2007; Nambisan et al., 2017; Pentland and Feldman, 2007). Over the past decades, scholarly attention has advanced understanding of the entanglement of digital technologies in organizations (Orlikowski, 2000; Nambisan et al., 2017). We know that people tend to use new digital tools in their work practice when they perceive these tools as beneficial to perform their tasks (Leonardi, 2011), and that digital technology can strongly affect the organization of work inside firms (Barley, 1990). For instance, Computer Aided Design (CAD) technology has pervaded work practices in architectural firms, and over the years has become indispensable to the work of designers (Leonardi, 2011; Orlikowski, 2000). Use of a pervasive digital technology by multiple individuals has repercussions at the level of firms, organizations or - to put it most generally - collectives (Burton-Jones and Gallivan, 2007; Leonardi, 2013).

Within collectives, the use of a digital technology by individual actors needs to be organized to realize collective-level goals (Leonardi, 2013; Nambisan et al., 2017; Yoo et al., 2010, 2012). This organization may result in a shared usage structure, in which individual actors use a digital technology in a similar way (Leonardi, 2013). Yet since digital innovations draw on the heterogeneous knowledge resources of multiple, autonomous actors (Yoo et al., 2010), a differentiated usage structure is generally more appropriate. Therefore, digital-innovation research needs to study how to organize the usage of digital technology by heterogeneous actors into a collective product or service (BurtonJones and Gallivan, 2007; Leonardi, 2013; Nambisan et al., 2017). Although such organization activities are said to be widespread in dynamic and complex practice (Burton-Jones and Gallivan, 2007; Nambisan et al., 2017), there are only few detailed analyses of actual organization activities (Leonardi, 2013).

A better understanding of the actual organization of digital-technology usage is needed in at least three respects: new forms of organizing to which pervasive digital-technology usage gives rise (Yoo et al., 2012); collective appropriation of parts of a new digital technology to realize collective goals (Leonardi, 2013); and actual processes of digital innovation (Nambisan et al., 2017). Gaining this understanding

\footnotetext{
* Corresponding author.

E-mail addresses: g.p.j.verstegen@tue.nl (L. Verstegen), w.n.houkes@tue.nl (W. Houkes), i.m.m.j.reymen@tue.nl (I. Reymen).
} 
requires studying digital-technology usage as a multi-level process, in which collective-level outcomes emerge on the basis of combinations of individual-level heterogeneous actions (Burton-Jones and Gallivan, 2007; Yoo et al., 2010; Nambisan et al., 2017).

In this study, we aim to answer the following research questions: "How do individual actors use digital technology, how do these actors organize its use in collectives, and how do they organize their work with that of other actors in order to realize collective-level goals?" We study the activities of individual actors who work with new and established digital tools. We apply an affordance perspective (Chemero, 2003; Faraj and Azad, 2012; Gibson, 1977; Leonardi, 2011, 2013; Norman et al., 1988; Zammuto et al., 2007) to analyze in particular the collective level (Felin et al., 2012; Kozlowski and Klein, 2000).

Our study focuses on the usage and organization of a new, pervasive digital technology (Building Information Modelling) in dynamic and complex work practices, both on the individual and collective level. We study architectural design practice, where digital tools are used to produce output (Becker and Lazaric, 2009; Pentland and Feldman, 2007) in the form of artifacts: sketches, plans, or models that serve multiple purposes in the design of buildings (Boland et al., 2007; Ewenstein and Whyte, 2009). The design of buildings is a work practice that serves as a good exemplar for studying how the usage and organization of digital technologies affects multiple, autonomous actors with distinct expertise (Boland et al., 2007) who work towards collective-level goals (Leonardi, 2013). We implemented a qualitative research design, based on interviews in two architectural firms, complemented with observations and archival data (Yin, 2011).

By analyzing interactions of multiple individual actors with digital technology, we identified two collectives in which actors organize usage - architectural design teams and work groups - through activities that we call configuring-in-use and reflecting. By analyzing how these two organizational activities are combined in order to enact affordances, we demonstrate how actors collectively organize digital-technology usage to realize collective-level goals. We identify the combination of these organizational activities as configurational usage (Kozlowski and Klein, 2000; Burton-Jones and Gallivan, 2007; Kane and Labianca, 2011).

We contribute to literature on the usage of pervasive digital technology by, firstly, providing a detailed empirical investigation of organized usage of BIM technology in architectural design practice. Based on this investigation, we conceptualize a process of configurational usage geared towards the enactment of collective affordances. Configurational usage combines the organizational activities of configuring-in-use and reflecting. These activities comprise a broad variety of individual-level interactions of actors. We show how, through these interactions, collective-level affordances are enacted in different ways. Secondly, we refine the conceptualization of configurational usage and thereby improve understanding of core processes of digital innovation. We identify the need for ongoing organization of technology usage to attain affordance enactment, for relaxation of structural boundaries of innovation by not focusing on preselected, traditional analytical levels, and for an explicit iterative multi-level focus.

The remainder of the paper is structured as follows: the next section describes current insights on individual and collective use of digital technology and identifies the need to study organization of digitaltechnology usage at interrelated individual and collective levels. The methods section describes the case study and how data is collected and analysed. Subsequently, the findings are presented. We conclude with a discussion of the implications for research on digital technology and innovation.

\section{Theoretical background}

Digital-technology usage is a key aspect of digital-innovation research (Nambisan et al., 2017; Yoo et al., 2012). This study responds to the research agenda proposed by Nambisan et al. (2017) to advance insights in processes of digital innovation. These processes are distributed, i.e., they draw on the heterogeneous knowledge resources of multiple, autonomous actors; combinatorial, i.e., they combine existing tools with new digital capabilities (Yoo et al., 2010); and generative, i.e., they are capable of producing unanticipated effects (Boland et al., 2007; Nambisan et al., 2017; Yoo et al., 2012). More specifically, this study focuses on the use of digital technology and the organization of this use, through distributed, combinatorial, generative processes, to achieve collective-level goals.

Previous studies have shown that usage of digital technology should not only represent individual actors' employment of new digital features, but also represent how this usage is organized in groups of actors (DeSanctis and Poole, 1994; Markus and Silver, 2008), and how digitaltechnology usage contributes to realizing group-level goals (BurtonJones and Gallivan, 2007; Nambisan et al., 2017; Orlikowski, 2000; Pentland and Feldman, 2007). The next subsections discuss the organization of individual and collective use of digital technology and identify the need for studying how they are combined in practice.

\subsection{Individual use of digital technology}

On the individual level, digital-technology usage can be conceptualized by categorizing interactions with digital technology by individual actors. An 'interaction' is any activity of an individual that is locally meaningful (Orlikowski, 2000), i.e., that is identified by an actor in describing their work practice, possibly in relation to their organizational role or membership of a collective. Choosing interaction with digital technology as the basic unit of analysis means that a single described activity (see Section 3: 'Research methods') can be categorized as multiple interactions (Gaskin et al., 2014; Pols, 2012). Moreover, understanding technology usage through variegated individual interactions takes into account the multiplicity, partiality and fragmentation of digital technologies (Yoo et al., 2010). Technology usage - understood as "an individual user's employment of one or more features of a system to perform a task" (Burton-Jones and Straub, 2006) - is multidimensional and context-dependent. Any empirical investigation into technology usage needs to conceive of technology as multiple and partial (Orlikowski and Iacono, 2001); it should take into account how different individual human actors within the same organization employ various features of interrelated digital tools, even while working on the same collective task (DeSanctis and Poole, 1994; Markus and Silver, 2008). Users can enact technologies differently based on their individual expertise and knowledge (Leonardi, 2013). They can also modify technology by making changes in the hardware, software, norms and rules, and in their own knowledge (Orlikowski, 2000).

\subsection{Collective use of digital technology}

For working on a collective task, technology usage of individual actors needs to be organized. Digital-technology usage involves more than taskrelated exchanges or individual interactions with digital technology by independent actors. Rather, technology usage in complex work practices involves interdependent tasks (Burton-Jones and Gallivan, 2007), i.e., tasks that depend on each other's input for successful completion or for a more encompassing success.

We call a group of multiple individual actors who work on the same collective task through performing interdependent individual-level tasks, a collective. An example of a collective is a design team, in which actors work to complete a joint design task. Design practice is strongly heterogeneous with regard to actors, tools, and tasks. Thus, interdependencies can be expected between individual-level tasks and interactions in this organizational context. Dealing with these interdependencies requires collaboration, communication and coordination during usage (Karsten, 2003; Burton-Jones and Gallivan, 2007; Leonardi, 2013). Although such organizational activities are said to be widespread in dynamic and complex practice (Burton-Jones and Gallivan, 2007; Nambisan et al., 2017), there are few detailed analyses of actual 
organization of digital-technology usage (Leonardi, 2013).

We capture task interdependency by analysing enactment of collective affordances. We take a relational view of affordances: they are features of a technology that are perceived by actors as offering them possibilities for goal-oriented actions (Norman, 1988; Markus and Silver, 2008). Perceptions of actionability depend on an actor's intentions, expertise and goals (Chemero, 2003), as well as possible enabling and disabling effects of the local context (Nambisan et al., 2017). As "multi-faceted relational structures" (Faraj and Azad, 2012), affordances are here said to be enacted rather than created (as in Leonardi, 2013), if they are perceived as actionable by at least one actor. Collective affordances are features that are perceived by at least one actor as offering possibilities for goal-directed actions of multiple members of a collective (Leonardi, 2013). Collective affordances may include new benefits, such as increased revenue or reduced workload, as well as existing benefits, such as flexibility in creative design (Boland et al., 2007). Digital tools and algorithms can be combined to generate new usage potential (Henfridsson et al., 2018), triggering so-called 'wakes' of innovation (Boland et al., 2007).

Digital-technology usage by heterogeneous actors needs to be organized in order to enact collective affordances. While the organization of digital technology usage may take many forms, studies have suggested exemplary ways to organize the contributions of individual actors towards a collective-level goal. A comprehensive example is provided in a comparative study by Leonardi (2013). In this work, two engineering groups of a car manufacturer started using a new simulation tool. Here, enactment of a collective affordance required organizing the usage by, potentially, all members of the collective. It was found that the new digital technology was only turned into a resource by the collective that converged towards a shared usage structure, in which all individual actors use the digital technology in a similar way. In a digital world, actors are more likely to be specialized in specific tasks (i.e., heterogeneous). Therefore, attaining a shared pattern of use can be difficult or undesirable (Leonardi, 2013; Nambisan et al., 2017). In these heterogeneous settings, different members of a collective may perceive different actionable features of a digital technology. To improve understanding of digital-technology usage in complex work practices, we need to study how heterogeneous individual-level interactions are organized to realize collective-level goals (Burton-Jones and Gallivan, 2007; Kozlowski and Klein, 2000).

\subsection{Combining individual and collective use of digital technology}

Digital-technology usage should be studied by combining individual and collective levels of analysis. Usage of technology in complex and dynamic innovation processes cannot be captured solely on a collective level. Organization of digital-technology usage involves coordination of interactions by individual actors, working towards collective-level goals through performing interdependent tasks (Burton-Jones and Gallivan, 2007). Conversely, an exclusive focus on interactions by individual actors with digital technology may not provide insights in the value that digital-technology usage produces for a firm or other collectives (Burton-Jones and Gallivan, 2007; Henfridsson et al., 2018).

Organizing usage of technology has been studied by choosing specific analytical levels. For instance, Dossick and Neff (2009) separate the individual, project, and firm level in their analysis to show conflicts between them. In recent work, the detailed analysis of Lobo and Whyte (2017) provides insights into the interface between multiple projects and firms. To leave room for emergent structures (Nambisan et al., 2017) we do not, at the collective level, distinguish in advance between project, firm, and inter-organizational analytical levels. In our view, both established and emergent structures can be identified at the collective level, based on the importance that actors assign to them.

Only by studying digital-technology usage on combined individual and collective levels of analysis, insight can be created into processes of organizing individual heterogeneous technology usage for realizing collective-level goals - like processes of organizing shared-usage structures in homogeneous settings. Organizing the contributions of individual actors towards enactment of collective affordances is known in the literature as configurational usage (Burton-Jones and Gallivan, 2007; Kane and Labianca, 2011; Kozlowski and Klein, 2000). Here, a configuration ('configuration of usage'; Burton-Jones and Gallivan, 2007) refers not merely to a collection of tools, but primarily to a more or less stable pattern of interactions with digital technology by one or more actors. This does not assume a pre-established, static configuration brought about by prior central planning or technological constraints. Rather, enactment of collective affordances requires an ongoing process of organizing the usage of technology, coincident with the usage itself. This process is unlikely to comprise the same interactions in different organizations, even if they implement the same technology. An analysis of configurational usage might not only bring out what unity there is in the diversity of technology usage, but also just how much diversity is preserved in or enabled by technology usage (Nambisan et al., 2017).

There is a scarcity of empirical research on the organization of digital-technology use in which individual and collective levels of analysis are combined (Burton-Jones and Gallivan, 2007). Thereby, opportunities are missed for detailed insights into the organization of individual heterogeneous technology usage for realizing collective-level goals. This study aims to fill this important gap in digital-innovation studies.

\section{Research methods}

Our study focuses on the usage and organization of a new, pervasive digital technology in architectural design practice. The design of buildings is a work practice that serves as a good exemplar for studying how the usage and organization of digital technologies affects multiple, autonomous actors with distinct expertise (Boland et al., 2007), who work towards enacting collective affordances (Leonardi, 2013). We performed a qualitative study, aimed at obtaining in-depth insights into individual-level interactions with digital technology, organization of usage of digital technology, and collective affordance, enabling theoretical inference (Eisenhardt and Graebner, 2007; Gerring, 2007).

\subsection{Case selection: Building Information Modelling (BIM) in architectural firms}

Architectural firms are experiencing the introduction and pervasion of new digital technology, called Building Information Modelling (BIM). BIM comprises digital tools and methods that do not only offer opportunities for sharing information among multiple parties (Whyte, 2011), but that also affect the epistemic processes involved in building design (Ewenstein and Whyte, 2009), and thereby the way in which architectural firms provide services to their customers. Working with BIM implies variegated usage of BIM tools in architectural design practices, which generally involve multiple, autonomous actors with distinct expertise and thus feature processes of organizing individual heterogeneous technology usage for realizing collective-level goals. Various tools are used to construct design artifacts, which provide information for a later point in time in the building process. One prominent tool for constructing these objects in a BIM configuration is Revit, which enables users to 'draw' in a 3D digital environment. By inserting geometric and parametric information, a virtual spatial model of a building is designed. BIM has been introduced in work practices that involve incumbent digital tools, such as 2D Computer Aided Design (CAD) software or 3D sketching software (Azhar, 2011). Still, BIM technology is viewed as a more potent digital technology by many practitioners throughout the AEC industry (Azhar, 2011). Studies have shown that the implementation of BIM technology can have substantial firm-level and sector-level effects, such as reducing costs in building projects by avoiding mistakes (Bryde et al., 2013). 
We conducted a case study into the usage of BIM technology in two architectural firms in the Netherlands. Initial interviews with leaders of eleven architectural firms of different sizes in the Netherlands indicated the following case-selection criteria to collect sufficiently rich data on individual-level interactions, usage of digital technology within architectural firms, and collective-level affordances: active engagement with BIM by actors in the firm; experience with BIM; presence of BIM manager; and completion of projects with BIM. From the registry of architectural firms in the Netherlands, five firms remained, two of which (Alpha and Beta) were selected and agreed to participate in the study. Firm characteristics were similar in that both firms have completed multiple projects using BIM, have more than five years of experience with BIM, organize the use of BIM within their firm, operate internationally, are financially healthy, and use similar BIM tools. Within the limitations of these criteria, we applied maximum variation sampling to detect diverse interactions with BIM technology. This enabled the recognition of shared patterns, emerging from the heterogeneity in roles within architectural firms (Patton, 2002).

\subsection{Data collection}

Data was collected by participation in BIM conferences and focus groups and for both firms on individual and collective level, via interviews, archival data and observations. We obtained insight into BIM tools, interactions with the BIM tools by actors in the firms, and collective affordances. Table 1 presents an overview of the data collected.

To gain expertise on BIM, and to be able to make more informed choices (Tsoukas and Chia, 2002), the first author joined the BIM community by participating in BIM-specific conferences in 2013 and 2014. Field notes were made and presentation documents and minutes of the seminars were gathered. Additionally, this author joined three focus groups, starting in 2014. The first group consisted of 15 professionals working with BIM in different architectural design firms in the Netherlands. This focus group met four times in 2014, once before, twice during, and once after the interviews in firms Alpha and Beta. Sessions lasted for three hours and each session had its own specific topic related to the organization of BIM technology. The overall topic was 'organizing BIM', with sub-sessions on BIM tools, BIM processes, and organizing for BIM. Two of the meetings were fully recorded and transcribed, and minutes and presentations from all meetings were collected. This data was used for case selection, and triangulation of interviews. The second focus group consisted of more heterogeneous actors, and discussed broader topics, such as BIM usage in areas of: contract manufacturing, sustainability predictions, sub-contracting, production, and professional education. This group met two times in 2015. Field notes were made, and were complemented with minutes of meetings and presentations. These data served as input for case selection, interview questions, and preliminary versions of the coding scheme. After an initial draft of the study, validating findings, and discussing the practical relevance of the findings of the study, the first author participated in a third focus group in 2017, to check the face validity of the data. Furthermore, additional data was informally
Table 2

Interviewee background information in two firms.

\begin{tabular}{llll}
$\begin{array}{l}\text { Identification character } \\
\text { interviewee }\end{array}$ & $\begin{array}{l}\text { BIM Expertise } \\
\text { Level }\end{array}$ & $\begin{array}{l}\text { Years of experience } \\
\text { in }\end{array}$ & Role \\
\cline { 3 - 4 } & BIM Archi- \\
tecture
\end{tabular}

\begin{tabular}{lllll}
\hline \multicolumn{2}{l}{ Firm Alpha: $100-130$ employees } & & & \\
$\mathrm{A}$ & High & 5 & 10 & BIM Manager \\
$\mathrm{B}^{\mathrm{b}}$ & High & 5 & 8 & Architect \\
$\mathrm{C}^{\mathrm{c}}$ & High & 5 & 11 & Architect \\
$\mathrm{C}^{\mathrm{c}}$ & Medium & 3 & 3 & Architect \\
$\mathrm{D}^{\mathrm{b}}$ & Medium & 5 & 17 & BIM Manager \\
$\mathrm{E}^{\mathrm{b}}$ & High & 5 & 10 & Engineer \\
$\mathrm{F}$ & Low & 1 & 11 & Project Manager \\
$\mathrm{G}$ & Indirect & - & - & System Admin \\
$\mathrm{H}^{\mathrm{b}}$ & High & 4 & 4 & Engineer \\
Firm Beta: $50-100$ employees & & & \\
$\mathrm{I}^{\mathrm{d}}$ & High & 7 & 7 & BIM Manager \\
$\mathrm{J}^{\mathrm{b}}$ & High & 6 & 15 & Engineer \\
$\mathrm{K}^{\mathrm{b}}$ & Low & 6 & 23 & Project Manager \\
$\mathrm{L}^{\mathrm{b}}$ & Indirect & 1 & 15 & Engineer \\
$\mathrm{M}^{\mathrm{b}}$ & Low & 6 & 10 & Architect \\
$\mathrm{N}^{\mathrm{N}}$ & Indirect & - & - & System Admin \\
\hline
\end{tabular}

a Identification characters are assigned chronologically.

b Work practice of interviewee was also observed.

c Interviewees were interviewed together.

d Interviewee was interviewed twice.

e Range is specified to ensure anonymity.

collected through all focus groups, by receiving feedback from multiple professionals on preliminary ideas and findings of this study, increasing the validity of the findings.

Data for the main analysis was collected during 2014 in firms Alpha and Beta by interviewing actors who work with BIM in different formal roles (e.g., architect, BIM manager, or engineer). Eight interviews were done at Alpha and seven at Beta. The interviews were semi-structured for replication purposes, focusing on the BIM-related work practices of the interviewee. During the interview, interviewees were asked about their personal history and role within the firm, and then about their experience with BIM. Subsequent topics included perspectives on BIM, interactions with tools (hardware and software), activities involving other actors, daily work processes, expectations from the firm, and benefits of BIM for the firm. Data collection was performed by visiting a firm for a full day, starting with a semi-structured interview with the BIM manager of the firm, and continuing with other selected employees, where interviews were pre-arranged by the BIM manager. During the visit, we probed for the interviewees' perception of who is important in any BIM-related processes to complete the list of roles. Table 2 provides an overview of the interviewees in the two firms: their BIM expertise level, years of BIM and general working experience in architecture, and role. Interviews lasted one hour on average and were conducted by one or two interviewers. Interviews were fully recorded

Table 1

Data collection overview.

\begin{tabular}{|c|c|c|c|c|c|c|}
\hline & \multicolumn{3}{|c|}{ Data sourced from } & \multicolumn{3}{|c|}{ Data sourced on } \\
\hline & Company Alpha & Company Beta & Other & Tools & Interactions & Collective affordance \\
\hline BIM & & & 6 & $\mathrm{x}$ & $\mathrm{x}$ & $\mathrm{x}$ \\
\hline \multicolumn{7}{|c|}{ Seminar/focus group sessions } \\
\hline \multirow[t]{2}{*}{ Interview } & 8 & 7 & - & $\mathrm{x}$ & $\mathrm{x}$ & $\mathrm{x}$ \\
\hline & & & 11 & & & $\mathrm{x}$ \\
\hline \multirow[t]{2}{*}{ Archival data } & 15 & 15 & - & $\mathrm{x}$ & $\mathrm{x}$ & $\mathrm{x}$ \\
\hline & & & 12 & & & $\mathrm{x}$ \\
\hline Observation & 4 & 4 & & $\mathrm{x}$ & $\mathrm{x}$ & \\
\hline
\end{tabular}


and transcribed.

Data collection was complemented with archival documents in order to obtain information on artifacts, BIM tools, and collective-level effects. This included information from the firm website: current and finished projects, vision on BIM, employee data; information from the chamber of commerce: annual reports and vision statements; and from public media: company presentations, newspaper articles, web articles, online videos, podcasts and public interviews. This additional data was used to prepare for interviews, spark discussions, and triangulate interview data. For further triangulation, we observed eight people (four in each company) during their performance of BIM-related tasks, creating in-depth insights into interactions with digital tools in daily work practices. The observations lasted between 20 and $30 \mathrm{~min}$, and were performed to elaborate on specific subjects discussed during the interviews. For example, an engineer demonstrated how (s)he used specific software, and a project manager showed how formal documents were used.

\subsection{Data analysis}

To answer the research questions, we analyzed the data in three steps. In the first step, we identified in the data of both cases: interactions with BIM technology by individual actors; tools used; and collective affordances of BIM usage. In the second step, we analyzed how actors organize the usage of BIM technology in collectives. In the third and final step, we analyzed how actors collectively configure digital technology to enact collective affordances.

In the first step, we iteratively developed a coding scheme within the author team, based on analysis of the raw data (interviews and observations) and literature study. The coding scheme was refined by two authors who independently coded four interviews, with a final interrater reliability of 0.91 for the fourth interview. The coding scheme consists of the following three concepts and related subcategories: interaction, tool, and collective affordance. Table 3 represents the coding scheme with a definition of these concepts and their subcategories, empirical indicators, and illustrative quotes.

The interviews were independently coded by two authors on the basis of the coding scheme, using Nvivo software. The interviews with eleven leaders of architectural firms were coded only for collective affordances. Differences between coders were resolved through discussion with the third author, and by triangulation with observations, archival data, and data obtained from BIM seminars.

The coding process resulted in an overview of interactions, tools, and collective affordances. The first concept is that of interactions with BIM technology by individual actors. One such interaction is 'constructing', e.g., creating a drawing with a pencil. Since we examine the nexus of technology and organization (Pentland and Feldman, 2007), we distinguish two main subtypes of interactions. Firstly, in technological interactions, actors are primarily engaged in using technological tools to perform an individual-level or collective-level task (e.g., using a software tool to draw a three-dimensional model of a building). Secondly, in organizational interactions, actors primarily engage in using organizational tools to facilitate usage of digital technology by other actor(s) (e.g., using a planning tool to manage when architects work on drawings for a specific project). This distinction concerns the primary focus of actors' perceptions in their interactions with digital technology (Gaskin et al., 2014). Therefore, it does not reflect one of the dualist approaches to the technology-organization relationship that are rejected in practice theory (Feldman and Orlikowski, 2011).

Four interactions with BIM tools, all resulting in an artifact, were categorized as technological: constructing, converting, reviewing, and structuring. Five other interactions were categorized as organizational: formalizing, transferring, communicating, learning, and coordinating. We found one instance of a third subtype of interactions. In the interaction changing system components, an actor adapts (parts of) the BIM technology, for example by adding new computer hardware or installing new software.

The second concept is that of tools, defined as artifacts that can be used by an actor to perform a task. Design activities involve interacting with these tools to create further artifacts. The distinction between tools and artifacts is relative to what is analyzed: what is produced in one interaction may be used in later interactions to produce further outputs; it may be represented as an artifact in the former interaction, and as a tool in the latter. We distinguish two types of tools. Technological tools can be used by actors to perform BIM tasks; an example is design software. Organizational tools can be used by actors to perform an organizational task; examples are rules and policies. The third concept is that of collective affordances of BIM-technology usage. Examples are increased efficiency, or improved collaboration with other parties in building projects.

In the second step, we tried to understand how actors organize the usage of BIM in collectives. From the analysis of the interactions in collectives, we distilled two activities. We named the first activity configuring-in-use. Typically, interactions of actors involved in design work fall in this category. The technological interactions in this category of configuring-in-use are constructing, converting, reviewing, and structuring; organizational interactions are communicating, coordinating, learning, and transferring. The second activity is named reflecting. This activity includes the organizational interactions communicating, coordinating, and formalizing. Additionally, this category contains interactions in which tools are adapted through deliberately changing system components. By analyzing the activities on the collective level, we found two main type of collectives in the data: configuring-in-use is performed in architectural design teams, and reflecting is performed in work groups. Most interviewees mentioned or referred to these collectives.

In the third and final step, we analyzed how actors configure BIM usage to enact collective affordances. Here, we produced an overview of the affordances, and related them to the two activities identified in the second step. By analyzing the enactment of collective affordances, we were able to describe the process of configurational usage, resulting in an in-depth understanding of BIM technology usage in architectural design practice.

\section{Findings}

Our analysis started with investigating how individual actors use digital technology, and providing an overview of the highly diverse interactions with BIM technology found in both cases. Secondly, we analyzed how actors organize the usage of digital technology in collectives. We found two organizational activities for BIM technology usage: configuring-in-use and reflecting. Thirdly, we studied how actors organize their work with that of other actors in order to realize collective-level goals. By connecting the organizational activities to collective affordances, we revealed an ongoing process of configurational usage of BIM technology. Fig. 1 depicts an overview of the structure of the findings.

\subsection{Individual usage of BIM technology in architectural design practice}

We found many instances of individual actors using BIM technology, i.e., interactions. In the activities described by the interviewees in firms Alpha and Beta, we identified 12 types of interactions related to BIM technology. Our coding scheme in Table 3 contains for each type a definition, empirical indicators, and an illustrative quote. The most frequently reported interaction constructing, for example, is defined as creating or developing a model, and is signaled by adding or drawing a spatial object in a model, detailing a model, or modelling. In a specific instance of constructing, an architect may draw a wall for a building using 3D-design software (e.g., Sketchup or Revit). In general, the types of interactions are well distributed over the different interviewees. All interviewees referred to one or more organizational interactions; this includes engineers and architects whose formal role suggests that they 
Table 3

Coding scheme.

\begin{tabular}{|c|c|c|c|}
\hline $\begin{array}{l}\text { Concept } \\
\text { Interaction with BIM } \\
\text { technology }\end{array}$ & $\begin{array}{l}\text { Definition } \\
\text { An interaction is the performed task of actor(s) } \\
\text { who work with BIM technology; }\end{array}$ & Empirical Indicators & Illustrative quote \\
\hline Constructing & Creating or developing a model; & $\begin{array}{l}\text { Adding object, or drawing object in a } \\
\text { model, detailing, modelling; }\end{array}$ & $\begin{array}{l}\text { In the initial phase we determine the design, so we also } \\
\text { draw constructive walls. }\end{array}$ \\
\hline Modifying & Modifying information in a model; & $\begin{array}{l}\text { Adapting object that were created by } \\
\text { another person, optimizing objects, } \\
\text { creating families; }\end{array}$ & $\begin{array}{l}\text { That a structural engineer adjusts a constructive wall } \\
\text { without notice, because he can access the model directly. }\end{array}$ \\
\hline Converting & $\begin{array}{l}\text { Converting information from one artifact type to } \\
\text { another artifact type; }\end{array}$ & Converting a model, printing to PDF; & $\begin{array}{l}\text { When I am finished, I'll have a set of drawings. I print } \\
\text { them to PDF, and then I will place them somewhere. }\end{array}$ \\
\hline Reviewing & Reviewing a model; & $\begin{array}{l}\text { Verifying a model with other tool } \\
\text { and/ or artifact; }\end{array}$ & $\begin{array}{l}\text { We receive a } 3 \mathrm{D} \text { model from the structural engineer and } \\
\text { then we check to see if it works with what we have } \\
\text { modelled. }\end{array}$ \\
\hline Structuring & $\begin{array}{l}\text { Adding structure to a model to make the model } \\
\text { useful for several purposes; }\end{array}$ & $\begin{array}{l}\text { Adding folder, layer, code, object } \\
\text { naming, or applying rules to a model; }\end{array}$ & $\begin{array}{l}\text { So you check, do those drawings have a certain code? } \\
\text { That [code] is included in a drawing list. So then, can you } \\
\text { assign your folders the same code? }\end{array}$ \\
\hline Showing & Viewing/ showing information in a model; & $\begin{array}{l}\text { Looking at the model, showing the } \\
\text { model to other person }\end{array}$ & $\begin{array}{l}\text { With Skype you can share your screen, so then we can } \\
\text { show what happens immediately. }\end{array}$ \\
\hline Formalizing & Formalizing what, how, when to model by whom; & $\begin{array}{l}\text { Creating instruction manual, BIM } \\
\text { protocol, rules; }\end{array}$ & $\begin{array}{l}\text { In the BIM protocol, the specifications of the BIM-model } \\
\text { are determined, software, exchange formats. }\end{array}$ \\
\hline Coordinating & Arranging work process indirectly related to BIM; & $\begin{array}{l}\text { Delegating activity, composing team, } \\
\text { aligning process; }\end{array}$ & $\begin{array}{l}\text { I meet up with my team at the department of } \\
\text { architectural engineering, and I can directly distribute the } \\
\text { work. }\end{array}$ \\
\hline Transferring & $\begin{array}{l}\text { Transferring model information from location A } \\
\text { to location B; }\end{array}$ & Sending, uploading, synchronizing; & $\begin{array}{l}\text { For third parties, we have an FTP server, to which we can } \\
\text { make our files available. }\end{array}$ \\
\hline Communicating & $\begin{array}{l}\text { Communicating about a model or about } \\
\text { modelling through media other than BIM (phone, } \\
\text { skype, email, face to face, meeting); }\end{array}$ & $\begin{array}{l}\text { Emailing, calling, skyping, sending } \\
\text { pdf, showing, viewing a model; }\end{array}$ & $\begin{array}{l}\text { What we usually agree upon is that there is direct } \\
\text { communication during modelling. We usually use Skype } \\
\text { for this purpose, just chatting, because calling takes too } \\
\text { long. }\end{array}$ \\
\hline Learning & $\begin{array}{l}\text { Absorbing or sharing knowledge about BIM } \\
\text { activity or tool; }\end{array}$ & $\begin{array}{l}\text { Learning new skill in a course, } \\
\text { guiding other actor, hiring a BIM } \\
\text { expert; }\end{array}$ & $\begin{array}{l}\text { So we have attracted several professionals with lots of } \\
\text { experience in the field of BIM, to structure it in the firm. }\end{array}$ \\
\hline $\begin{array}{l}\text { Changing system } \\
\text { components }\end{array}$ & $\begin{array}{l}\text { A system interaction is also indirectly related to } \\
\text { the use of BIM technology, performed by actor(s) } \\
\text { who change components in the BIM system. }\end{array}$ & $\begin{array}{l}\text { Installing software, upgrading } \\
\text { hardware; }\end{array}$ & $\begin{array}{l}\text { We said "all workstations must have an SSD drive, } \\
\text { meeting certain specifications, so we don't run into that } \\
\text { kind of trouble" }\end{array}$ \\
\hline Tool & $\begin{array}{l}\text { A tool is an artifact that can be used by an actor } \\
\text { to perform a task; }\end{array}$ & & \\
\hline Technological Tool & $\begin{array}{l}\text { A technological tool is an artifact that can be used } \\
\text { by an actor to perform a BIM task; }\end{array}$ & Software, hardware; & $\begin{array}{l}\text { Everyone has their own computer and, everything that } \\
\text { you need is installed, Revit and AutoCAD and you name } \\
\text { it. }\end{array}$ \\
\hline Organizational Tool & $\begin{array}{l}\text { A tool for organizing is an artifact that can be } \\
\text { used by an actor to perform an organizational } \\
\text { task; }\end{array}$ & $\begin{array}{l}\text { Agreement, contract, protocol, policy, } \\
\text { instruction manual, team; }\end{array}$ & $\begin{array}{l}\text { We do have certain guidelines on how we want to work } \\
\text { with certain software. }\end{array}$ \\
\hline Collective affordance & $\begin{array}{l}\text { Collective-level result of BIM interactions by } \\
\text { multiple agents }\end{array}$ & $\begin{array}{l}\text { Working more efficiently, requiring } \\
\text { fewer checks, improved productivity, } \\
\text { mistakes are found quicker; }\end{array}$ & $\begin{array}{l}\text { Yes, you notice less during construction, things get solved } \\
\text { faster... So indeed, if you're getting at a construction site } \\
\text { where no BIM process is used, then you sometimes see a } \\
\text { ventilation shaft appearing in the wrong room. And in } \\
\text { the process in BIM you did solve these issues even before } \\
\text { a contract manufacturer is involved. }\end{array}$ \\
\hline
\end{tabular}

would mostly use BIM tools. An overview of the occurrences of the interaction types for each interviewee is given in Table 4. The table displays the interactions (rows) mentioned per interviewee introduced in Table 2 (columns). For instance, BIM manager ' $A$ ' mentioned seven instances of constructing interactions, indicated by e.g.: adding object, or drawing object in a model. This table also shows our distinction between two main categories of interactions: technological interactions and organizational interactions (see also Section 3.3).

\subsection{Organization of BIM technology usage in collectives}

After analyzing individual-level interactions with BIM technology, we investigated how actors collectively organize their work with BIM technology. We present findings on the collectives in which organizing activities were found to be performed, and elaborate on these organizing activities.

\subsubsection{Architectural design teams and work groups as main collectives}

We found that actors identified most interactions with BIM technology as occurring in the context of architectural design teams and work groups. Architectural design teams work on design projects, which are the core business of architectural firms. In most of their interactions, actors perform project-related tasks using BIM tools: they work on plans, schematics and other artifacts geared towards the creation of a building. Multiple projects run in parallel, with varying contract forms, tasks, responsibilities and technologies, as well as varying collaborating parties such as construction engineers, consultants, installation experts, and sub-contractors. Work groups are concerned with specific technological BIM developments, such as new functionalities of design software. Actors can work in multiple architectural design teams and simultaneously be members of one or more specialized work groups. For instance, an architect can be a member of an architectural design team working on project 'Hotel Design' and a member of the work group 'BIM experts'. We found that, at the start of a project, technological and organizational BIM tools are formalized. Later, these tools and the performance of an architectural design team serve as input for work groups. When an architectural design team is finished, and BIM tools are adapted, some tools become obsolete. 
Research Question:

How do individual actors use digital technology?

How do these actors organize its use in collectives?

How do they organize their work with that of other actors in order to realize collective-level goals?
Findings
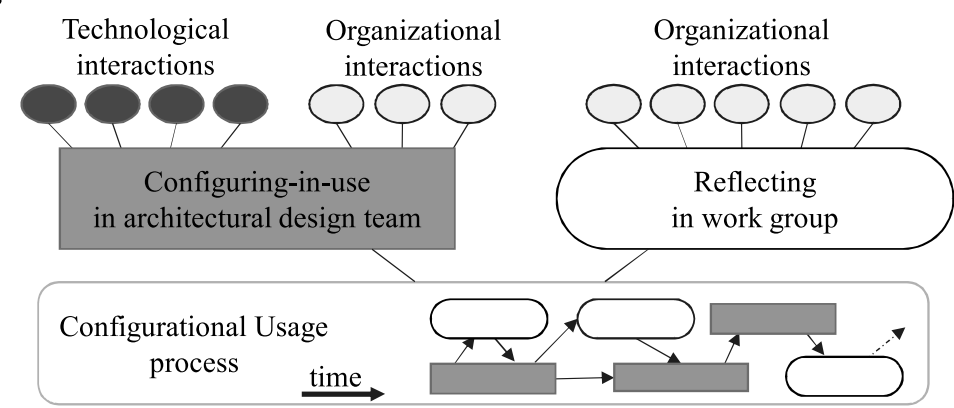

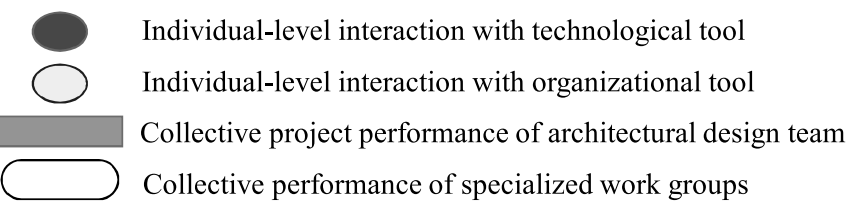

Fig. 1. Overview of findings related to the research questions.

Table 4

Interaction per interviewee, categorized for technological and organizational interactions.

\begin{tabular}{|c|c|c|c|c|c|c|c|c|c|c|c|c|c|c|c|}
\hline \multirow{2}{*}{$\begin{array}{l}\text { Role } \\
\text { ID interviewee }\end{array}$} & & \multicolumn{3}{|c|}{ BIM manager } & \multicolumn{3}{|c|}{ Architect } & \multicolumn{3}{|c|}{ Engineer } & \multicolumn{3}{|c|}{ Project manager } & \multicolumn{2}{|c|}{ System admin. } \\
\hline & & A & $\mathrm{D}$ & I & B & $\mathrm{C}$ & M & $\mathrm{J}$ & $\mathrm{H}$ & $\mathrm{E}$ & $\mathrm{L}$ & $\mathrm{F}$ & $\mathrm{K}$ & G & $\mathrm{N}$ \\
\hline \multicolumn{16}{|l|}{ Technological Interaction } \\
\hline & sum & & & & & & & & & & & & & & \\
\hline Constructing & 83 & 7 & 5 & 3 & 5 & 4 & 15 & 19 & 6 & 8 & 4 & 4 & 3 & 0 & 0 \\
\hline Modifying ${ }^{\mathrm{a}}$ & 14 & 5 & 0 & 1 & 1 & 1 & 1 & 0 & 2 & 1 & 0 & 0 & 2 & 0 & 0 \\
\hline Converting & 55 & 6 & 2 & 2 & 1 & 2 & 6 & 13 & 4 & 3 & 3 & 2 & 10 & 0 & 1 \\
\hline Reviewing & 49 & 5 & 1 & 1 & 3 & 2 & 3 & 11 & 2 & 8 & 5 & 3 & 4 & 1 & 0 \\
\hline Structuring & 19 & 0 & 0 & 0 & 0 & 0 & 3 & 0 & 0 & 4 & 12 & 0 & 0 & 0 & 0 \\
\hline Showing ${ }^{\mathrm{a}}$ & 14 & 1 & 0 & 2 & 0 & 2 & 2 & 2 & 0 & 2 & 1 & 1 & 1 & 0 & 0 \\
\hline Total sum & 234 & & & & & & & & & & & & & & \\
\hline \multicolumn{16}{|l|}{ Organizational Interaction } \\
\hline & sum & & & & & & & & & & & & & & \\
\hline Formalizing & 67 & 10 & 5 & 12 & 6 & 2 & 5 & 6 & 3 & 2 & 1 & 5 & 7 & 2 & 1 \\
\hline Coordinating & 65 & 15 & 3 & 7 & 2 & 1 & 1 & 7 & 0 & 8 & 4 & 6 & 4 & 1 & 6 \\
\hline Transferring & 60 & 4 & 1 & 7 & 3 & 5 & 7 & 14 & 3 & 5 & 0 & 1 & 6 & 0 & 4 \\
\hline Communicating & 63 & 2 & 1 & 1 & 3 & 6 & 10 & 12 & 2 & 8 & 4 & 2 & 8 & 0 & 4 \\
\hline Learning & 34 & 4 & 2 & 5 & 3 & 4 & 3 & 4 & 2 & 2 & 1 & 3 & 1 & 0 & 0 \\
\hline Changing system components & 29 & 2 & 0 & 3 & 0 & 0 & 0 & 4 & 0 & 0 & 0 & 2 & 0 & 7 & 11 \\
\hline Total sum & 318 & & & & & & & & & & & & & & \\
\hline
\end{tabular}

a These interaction types were removed from further analysis because they were insufficiently distinct from other interaction types.

\subsubsection{Organizational activities for BIM technology usage}

We found two different organizational activities concerning BIM usage: configuring-in-use, in which BIM technology is organized while it is used in architectural design teams; and reflecting, in which work groups consider BIM performances in projects. Each activity consists of a broad variety of interactions. The two organizational activities can be distinguished because they: (a) primarily occur within one of the two collectives described above; (b) differ from each other in the types of interactions that constitute them.

Configuring-in-use primarily occurs in architectural design teams, and consists of both technological and organizational interactions. A quote illustrates this activity, where an architect coordinates his interaction of constructing a model with a draftsman, and does so by communicating:

"So if you're in a final design phase, and I move that window-frame into a constructive wall [constructing], then I pass the message 'Caution, I have moved that object' [communicating] and then he is up to date [coordinating].”

What is characteristic here is the occurrence of organizational interactions (i.e., coordinating, transferring, and communicating) and technological interactions (i.e., constructing, converting, reviewing, structuring).

Organization of BIM usage can differ substantially between architectural design teams, even if they use the same tools and even if there are formal boundaries to the diversity of interactions within projects. These boundaries are required by the contextual dynamics of architectural design projects (e.g., involvement of different people, updates of design tools, new project requirements) and are formalized in protocols, to ensure that design-team members are guided towards predetermined project deliverables. For example, 2D pdf drawings are the final artifact type to be transferred to a customer. Yet within these boundaries or formal restrictions, activities of configuring-in-use have great potential for variation. Two examples, one from each case firm, illustrate how two instances of configuring-in-use may involve almost 
disjoint sets of interactions. We found that an architect at Alpha starts constructing an artifact directly with BIM tools when an initial sketch is drawn:

"You really work ... a lot with BIM. Almost $90 \%$ I would say, besides the time I spend on e-mail, meetings [...] There are just a few things that you really cannot do with [Revit], [...] when a sketch is defined, it works just fine in Revit. Then you are not restricted."

By contrast, in a comparable project, an architect at Beta coordinates his interactions with those of another actor, by frequently communicating with an engineer. This means that at Beta, an engineer and an architect are coordinating their parallel interactions of constructing and converting artifacts:

"I do not use Revit that much, not at all actually. But from the side line there is always someone from the drawing department going up along with me right from the start [coordinating], and we actually work in parallel. So what I am producing with sketches and AutoCAD [constructing] actually is translated directly [converting] by a draftsman into a $3 D$ model."

In Fig. 2, we visualize how the activity of configuring-in-use might comprise different interaction patterns, for projects that have the same deliverables.

In addition to configuring-in-use, we found an organizational activity that we call reflecting. This echoes Schön's (1987) reflection-onaction, where his reflection-in-action is similar to configuring-in-use. In reflecting, actors consider the interaction patterns in projects, and assess project performance with the firm's collection of organizational BIM tools. In contrast to configuring-in-use, reflecting occurs primarily in work groups and consists almost exclusively of organizational interactions (i.e., formalizing, coordinating, communicating, learning, and changing system components). For example in firm Alpha, one instance of reflecting involved multiple actors communicating in order to coordinate future technology usage by themselves or other actors throughout the firm, in multiple different projects:

"We have a '[BIM]-work group'; every once in a while we come together [coordinating] and discuss [communicating] the do's and don'ts [rules], what is going wrong, experiences with a project [...] If improvements are needed for certain things, then we think it through with everyone [collective of actors] and we come to a solution."

Instance of Configuring-in-use at Firm Alpha

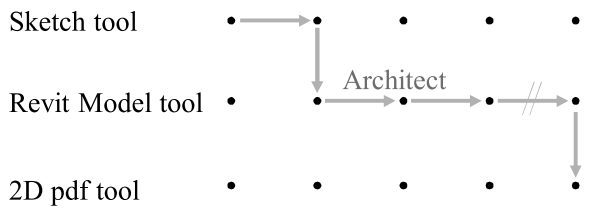

Instance of Configuring-in-use at Firm Beta

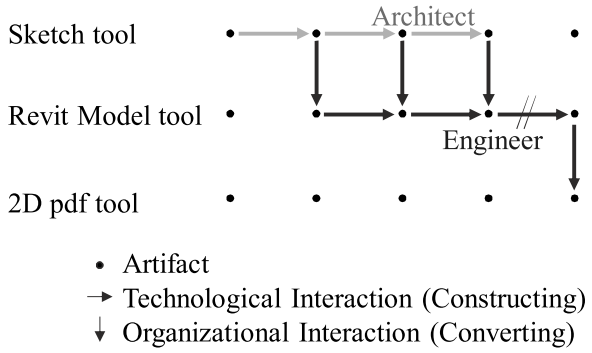

Fig. 2. Examples of different interaction patterns of configuring-in-use in architectural design teams in two case firms.
This collection of tools provides guidelines for the performance of a project. Based on discrepancies between the formal blueprint and actual performance, the actors in the work group may adapt the collection of BIM tools. These adaptations comprise various kinds of organizational interactions. Actors may, for instance, add or remove restrictions in formal documents and policies and thereby change the project boundaries, in order to improve interaction patterns in future projects. In both firms, this was done in specialized BIM work groups, consisting of members with extensive but diverse experience in architectural design teams. These work groups were tailored for coordinating BIM usage in the firm, by communicating regularly and coordinating interactions of actors, via formalizing organizational tools, such as rules. For instance, at Alpha, a Revit team consisting of 'super users' was responsible for disseminating best practices and knowledge, coordinating the constructing of models, and for having other actors learn to improve their ability to apply BIM tools. A policy was formalized, requiring the presence of at least one 'super user' in a project, to coordinate interactions among actors in daily work practice:

"We have several regular meetings within the firm, and one of them is the 'BIM-meeting' and one is the 'Revit-users' meeting. I'm involved in both. And in the 'BIM-meeting' arrangements are made about: protocols, how cooperation will be done both functionally and contractually. And these protocols are also analyzed for completed or ongoing projects. And based on that, the protocols are updated."

Another organizational interaction is changing system components. This includes updating design software, changing an internet service provider, installing a new server, or upgrading a computer hardware component. Here, we found interconnections between the organizational tools (e.g., rules, policy) and technological tools (e.g., hardware and software). For instance, when a software supplier released a new software version, it could only be included in projects when this fitted with specifications of a BIM protocol; otherwise, this inclusion would violate rules. The system administrator from firm Alpha provided an example of reflection and consequent change of BIM tools, illustrating the complexity of changing a single component of the BIM tools:

"Usually [in the BIM-meeting], what we do when a new version is released, we pass it by a select group of architects and draftsmen. And they will actually test it for architectural functionality and observe what happens if you convert a whole project; especially in collaborative projects, because then you depend on other firms. If you collaborate in one model, then you should be using the same version, or it won't work."

Features of BIM technology are changing periodically: software (Revit) is updated yearly, and is not fully backwards-compatible. Software updates must be carefully tested and implemented. Therefore, reflecting is not only performed on past projects, but also on new technological tools, and on how changing these may affect the use of BIM tools in future projects.

\subsection{Enacting collective affordances with BIM technology}

The previous findings concerned interactions at an individual level and organizational activities, which we identified as patterns of interactions in different collectives. These findings served as input to identify how collective affordances are enacted. We found an ongoing process of configurational usage, which combines the activities of configuring-in-use and reflecting.

\subsubsection{Collective affordances of BIM technology usage}

First, we coded all interviews for collective affordances that were explicitly related to BIM usage. For the coding scheme, see Table 3 . We found descriptions of collective affordances by all interviewees, even those not using BIM. In total, 232 collective affordances were mentioned, which we classified into seven different categories, namely income, creativity, efficiency, quality, condensation, collaboration, and 


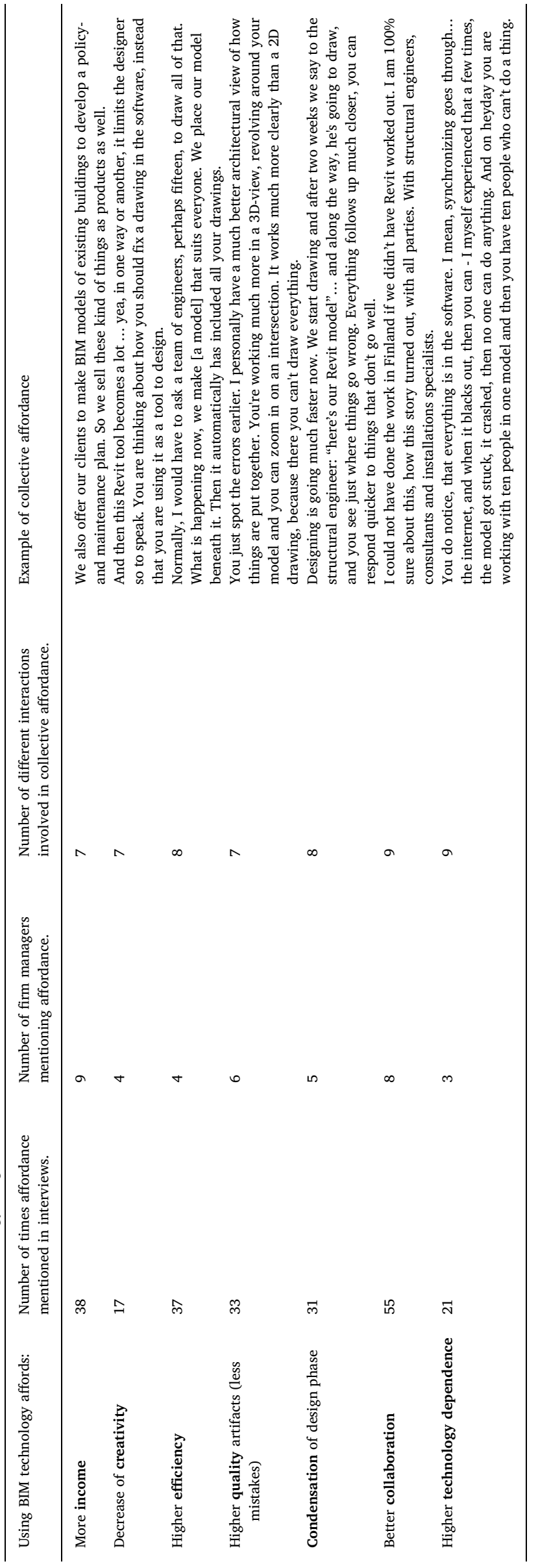

technology dependence. Examples of mentioned affordances and their classification are: higher-quality buildings (quality), lower failure costs (efficiency), shorter design cycle time (condensation), lower production costs (efficiency), lower total costs throughout the lifecycle of a building (efficiency and quality). Table 5 presents for each collective affordance an example from the data. The affordances in Table 5 were validated in the focus groups.

Some affordances relate to the collectives identified above, i.e., architectural design teams and work groups. Others relate to different collectives, such as the firm, professional roles (e.g., architects), or the AEC industry. For instance, collaboration was often identified as a collective affordance of BIM. This matches the frequently voiced expectation that using BIM technology improves collaboration in construction projects and decreases costs of projects by reducing the number and severity of mistakes (Azhar, 2011). Contrary to our prior expectations, we could not relate specific affordances to specific collectives. This does support our choice not to focus on specific collective levels. Moreover, some affordances were explicitly related to multiple collectives. We found a set of diverse affordances perceived by multiple individuals, without evidence of one dominant collective affordance. This shows the relativity of collective affordances.

\subsubsection{Towards configurational usage}

For each of the collective affordances identified, enactment in architectural design practice involves multiple, heterogeneous actors interacting with BIM technology in different - and occasionally, in similar - ways. Therefore, enactment requires organization of technology usage in collectives (Burton-Jones and Gallivan, 2007; Leonardi, 2013), i.e., what we call configurational usage. We found that configurational usage involves an iterative combination of configuring-in-use and reflecting, in an ongoing process that is never 'complete'.

An important goal stated for using BIM technology is to improve collaboration in construction projects. In firm Beta, an engineer was specialized in setting up BIM collaboration in projects. This person formalized BIM protocols for projects, to enable collaboration in design projects using BIM technology. Formalizing BIM usage for projects requires customization for each project. When performing the project, actors need to configure-in-use to deal with project-specific events. In addition, throughout projects, a BIM work group engages in reflecting so that future projects can be formalized with the new experience included:

"We do have defined certain agreements about how we want to work [...]. These are not very extensive. Sometimes, something new pops up. [...] Sometimes, it's trial and error. Then we approach such a project, and we know the basics. But then all sorts of things emerge, that we take into account in the next working agreements."

The example shows that configurational usage is a process that requires repeated combination of configuring-in-use and reflecting. BIM usage was formalized in every project, and the team repeatedly reflected on projects in order to update the protocols in later projects. Through this iterative combination, experience was built and applied.

We found that configurational usage also enables performing more advanced collaborative design projects. In Firm Beta, a project was started in which firms from five different countries were involved to design and build a state-of-the-art factory in Finland in an existing monumental building. By using new digital technologies, integrated into BIM, and aligning the organizational tools (e.g., BIM protocols, collaboration agreements, software guidelines), this advanced collaboration was enabled:

"This is what we do for an American customer, with a delegated client in London. With a local Finnish party, with a Belgian construction consultant and a British construction firm. And then a whole bunch of Finns around it. We all do that in BIM."

The CEO of Beta described a process of reflecting, in which a BIM 
work group in Beta communicated about past project performances, in order to formalize a protocol for this advanced project. After the requirements were formalized and the project started, the architectural design team still needed to engage in configuring-in-use throughout the project. For example, it turned out that the project enabled new laser scanning technology, for converting and transferring accurate data of the monumental building, thereby replacing the formal requirement of converting hundreds of archived drawings manually.

Configurational usage also enabled enactment of other affordances than collaboration, such as pursuing more income. At Firm Beta, actors formalized BIM protocols for collaboration in architectural design teams. Meanwhile, they also started to pursue more income for the firm by using BIM technology in collaborative design projects:

"BIM formalization does not always run parallel to contract formation. When I join the table, there is often already a contract, and discrepancies between the contract and what a construction firm wants with a model. [...] They need the model to be at a certain level of detail for use in construction preparation, while we only have a contract for a less detailed model. Then you already have a conflict. While we could also say in advance, "with a little more budget we can lift that model at a higher level, then they can use it later on." That is the negotiation; that is now my biggest frontier: to make BIM play a larger role in contract formation."

BIM had been formalized and used in nearly all projects at firm Beta, even when customers did not explicitly ask for it. Yet the firm managers wanted to generate more income through BIM usage, which was still limited due to the timing of contract formation. Therefore, a work group attempted to make BIM a more integral part of the AEC industry, claiming additional revenues for using BIM technology in design projects. To enact this affordance of more income, actors had to reconfigure their contract-formation processes, leading to continued configurational usage.

Unfolding complexities and dynamics complicate the enactment of a collective affordance and thus also require ongoing configurational usage. Multiple projects are performed in parallel, with often only partly overlapping timespans. Additionally, design projects in architectural firms have a long duration - often of several years. Before a project starts, the use of BIM tools is generally formalized in a contract, specifying particular hard- and software, artifact types (e.g., 2D pdf, Revit models), and project requirements. Once the firm commits to a contract, many BIM tools cannot be adapted for the duration of the project. As a consequence, work groups that reflect on past projects typically cannot implement improvements in other ongoing projects, although many problems that emerged in an earlier project could also (be foreseen to) emerge in other concurrent projects. Furthermore, the state-of-the-art in BIM technology continues to change rapidly, requiring renewed reflecting and configuring-in-use.

The difficulties resulting from unfolding complexities and dynamics are illustrated by a BIM manager from firm Alpha, when describing the problems in organizing BIM usage in the heterogeneous context of architectural design practice:

"Other people are involved in projects that started just after my project. The question is whether it will work in their projects. They have taken steps in new developments of BIM. But the issues [that I experienced in my project] still remain. [...] The [technological] tools are available, but the protocols are not. And each project you work with new people that are not used to each other's ways of working. You can handle and interpret a project in so many ways, reinventing the wheel every time. BIM is just a set of possibilities that should be used smartly. And there is still a lot to learn."

Organizing BIM usage thus requires coping with a set of changing tools that need to be carefully implemented in multiple concurrent projects, where each project has different requirements and task interdependencies. Therefore, despite organizational efforts to formalize
BIM usage in projects, the complexities and dynamics that are intrinsic to architectural design practice require repeated configuring-in-use in architectural design teams, in combination with activities of reflecting in work groups to transcend the temporal boundaries of architectural design teams. Configurational usage is, in other words, an ongoing process that continually combines configuring-in-use and reflecting.

\section{Discussion}

We studied how individual actors use digital technology, how these actors organize its use in collectives, and how they organize their work with that of other actors in order to realize collective-level goals. We provided much-needed in-depth insights into usage and organization of pervasive digital technology. In particular, we showed that a focus on the ongoing process of configurational usage provides insight into the usage of pervasive digital technologies in complex and dynamic practice, addressing a key challenge in the study of digital innovation (Nambisan et al., 2017). Our study also contributes to an improved understanding of digital innovation by suggesting a refined conceptualization of configurational usage.

\subsection{Configurational usage of digital technology}

To the literature on the usage of pervasive digital technology we contribute a detailed empirical investigation of organized usage of digital technology. This organized usage is a phenomenon said to be widespread in complex and dynamic practice (Nambisan et al., 2017), yet it has seldom been investigated in detail (Leonardi, 2013). We integrate our findings in Fig. 3. Configurational usage to enact collective affordances consists of combining two collective-level organizational activities: configuring-in-use and reflecting. These activities comprise individual-level interactions of actors, and can take many forms. Through these interactions, collective-level affordances are enacted in different ways. We detail our contribution by conceptualizing the relationship between individual-level and collective-level usage of digital technology, discussing the ongoing process of collective-affordance enactment, and providing insights into the organization of digitaltechnology usage in complex and dynamic design practice.

Our study has shown that configurational usage provides a way to understand how multiple individual actors organize digital-technology usage to realize collective-level goals. Differentiated individual use of a pervasive digital technology has repercussions on collective digitaltechnology usage (Leonardi, 2013). Interactions of individual actors and collective-affordance enactment have a dynamic and reciprocal relationship (Burton-Jones and Gallivan, 2007; Nambisan et al., 2017). We deepened the understanding of this relationship by conceptualizing how multi-dimensional and context-specific individual usage relates to collective digital-technology usage. We showed how a broad variety in usage by heterogeneous actors can be categorized into technological and organizational interactions, and we revealed two organizational activities. Configuring-in-use involves actors organizing their work with that of others while performing a collective task. Reflecting provides directions for future configuring-in-use through the adaptation of

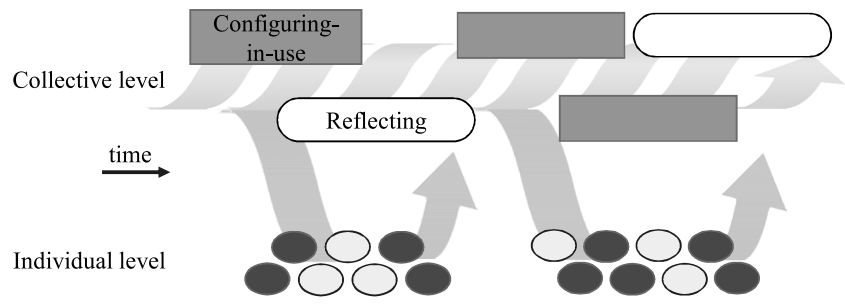

Fig. 3. Configurational usage: an ongoing process of combining Configuring-inuse and Reflecting [spiral] with repeated iteration [large arrows] between organization of individual-level and collective-level usage of digital technology. 
organizational and technological tools.

We found that configurational usage is an ongoing process, in which configuring-in-use and reflecting are repeatedly combined to enact collective affordances. We showed that enactment of affordances is not always planned upfront (Yoo et al., 2010); rather, enactment often emerges through changes in digital-technology usage. Enacting an affordance may require several instances of configuring-in-use and reflecting. Our relational conceptualization of enacting collective affordances as part of configurational usage has provided insights into the process of reaching collective-level goals with digital technology. However, configurational usage is not a linear path towards a single collective goal. Multiple affordances are perceived and enacting them requires configurational usage in specific situations, e.g., one project may involve an emphasis on efficient use of tools, while another project may leave more room to explore new functionalities of digital technology.

Our findings contribute specifically to the understanding of digitaltechnology usage in complex and dynamic design practice. In these practices, multiple paths are performed concurrently, through interdependent tasks in which actors need to adapt to changing technological and organizational states-of-the-art (Boland et al., 2007). Actors interact with BIM in different ways based on the diverse functionality provided by this digital technology. However, organizational tools (e.g., rules and guidelines) from established digital technology can restrict variation in the outcome of configuring-in-use with more emergent digital technology. These restrictions may hamper (or enable) the benefits of these emergent digital technology in unforeseen ways. As these organizational guidelines are often formalized into contracts at the beginning of long-term projects, restrictions in variation may have far-reaching consequences. We found that one way of organizing digital technology usage through reflecting involves the adaptation of organizational tools. These findings underscore the importance of repeated reflection on both established and emerging organizational tools towards use of digital technology, and of adapting them to realize collective goals.

\subsection{A refined conceptualization of configurational usage for studying digital innovation}

Usage of digital technologies is an important phenomenon in innovation research (Burton-Jones and Gallivan, 2007; Nambisan et al., 2017). Based on our insights on digital-technology usage, we can refine the conceptualization of configurational usage, and improve understanding of core processes of digital innovation. We specifically discuss three refinements: we add insights into the application of the affordance concept, we propose to relax structural boundaries of innovation, and we explicate an iterative multi-level focus.

First, our empirical study offers detailed insights into collective-affordance enactment applied in dynamic and complex contexts, and shows that affordance enactment requires ongoing organization. We have identified diverse affordances, and provided insight into the diversity that relates to enacting these affordances (Faraj and Azad, 2012). We found many ways to enact a collective affordance, often over the boundaries of firms, deepening understanding of how using new digital technology can bring about innovation, and how it changes organizations and other collectives (Nambisan et al., 2017; Yoo et al., 2012). We place emphasis on the process of enactment, rather than focusing on the presence of a collective affordance. Collective-affordance enactment does not necessarily lead to a state where a collective-level goal is realized or not (as in, e.g., Leonardi, 2013). Our study shows that configurational usage to enact collective affordances is a form of organizing by itself. We have therefore provided an example of the broad applicability of the affordance concept in studying digital innovation (Nambisan et al., 2017).

Second, we propose to relax structural boundaries of digital innovation. According to Nambisan et al. (2017), digital innovation requires rethinking the structural boundaries and sources for innovation. Our contribution lies in an approach that allows identification of important collectives that contain activities of configuring digital technology, which otherwise may have been omitted. We have distinguished an individual and collective level in the usage of digital technology. Thereby, we do not preselect traditional analytical levels, such as project, firm, inter-organization, or industry. Our conceptualization of configurational usage is well-equipped for studying processes of digital innovation in which structural boundaries exceed traditionally preselected analytical levels. It still allows for studying usage in more traditional project settings, while also capturing digital innovation in new temporal organizational structures that rely less on the boundaries of projects or even firms (Nambisan et al., 2017).

Third, we explicate an iterative multi-level focus. Studies on digital innovation should incorporate both individual-level and collective-level digital-technology usage. An exclusive focus on either collective activities or individual interactions would not get to the core of digital innovation. Digital-innovation processes are generative, combinatorial, and distributed (Boland et al., 2007; Nambisan et al., 2017; Yoo et al., 2010, 2012), and it is important to trace these phenomena to their source. People perform interdependent tasks, and these people change how they use and organize digital technology. Someone may just tap into a new functionality of digital technology, or work with someone from another organization with a slightly different view on how to organize their joint use. Yet, we would also like to learn which specific changes in policies or guidelines enable or restrict these individuals to innovate. Only by providing detailed insights into the ongoing organization of pervasive digital-technology usage within its specific, locally meaningful context (Orlikowski, 2000; Pentland and Feldman, 2007), and by incorporating the individual and collective level (Burton-Jones and Gallivan, 2007; Kane and Labianca, 2011; Kozlowski and Klein, 2000), we can capture digital innovation.

\subsection{Organizational implications}

Actors who operate in complex and dynamic digital environments may currently feel as puzzled about digital innovation as scholars do. We are aware that the understanding of digital innovation and collective usage of digital technology has not advanced to a point where we can provide concrete guidelines or design principles.

Our findings suggest that digital-technology usage comprises different organizational activities. Therefore, organizations should not focus exclusively on either configuring-in-use or reflecting. Rather, they should combine these activities based on actual problems and challenges that occur in work with the usage of digital technology. Even though standards and national regulations are developed for specific digital technologies, these standards can only serve as general benchmarks or baselines for an organization. Users need space to configurein-use the digital technology in the context of specific projects that all have unique requirements and challenges. Still, setting boundaries is needed to prevent undesirably broad perceptions of collective goals. By reflecting repeatedly on how digital technologies are used in projects, boundaries can be adapted in accordance with realizing a collective goal. Furthermore, our findings suggest that a mere focus on the collective is not enough to trace how digital technology pervades organizations. Organizations should be sensitive to changes in usage by individual actors, and should anticipate that these changes will affect how digital technology pervades the organization. By combining configuring-in-use and reflecting, digital technology usage can be steered in complex and dynamical practices, and hopefully managed in the (near) future.

\subsection{Limitations and suggestions for future research}

This study focused on dynamic and complex design practices, investigated through data collection in architectural firms. Further 
research is needed to study whether our results extend to uses of digital technology in complex practice outside our chosen context. However, our findings seem likely to hold in heterogeneous and complex practice, where the usage of a new digital technology is important for innovation.

An interesting direction of future research would be to represent the relationship between affordances enacted in hierarchically related collectives. It would be interesting to study outcomes in collective-affordance enactment compared to firm-level affordances and unified project-level affordances. When affordances are enacted by actors from different firms, these affordances will probably be enacted differently. The dynamics that emerge when these firms start to collaborate in a project by means of digital technology can provide insights into forces that bridge levels of analysis, or that even break down existing organizational structures. Within the limits of our study, we were able to identify several affordances related to different collectives (e.g., professional roles, industry, software suppliers), but investigating them systematically was outside the scope of this study. A comparative analysis of this sort would require a different approach than that taken in our exploratory study.

Furthermore, future research could focus on simultaneous enactment of multiple collective affordances, which may require further organization of interactions. Analyzing how multiple affordances are enacted simultaneously may enable a comparison between different usages of digital technology in terms of the strength of the collective affordances enacted. Especially when multiple affordances are enacted by different collectives working together in an organized way, the dynamics that emerge can provide insights into forces that steer innovation, and thus aid in the quest for understanding digital innovation (Nambisan et al., 2017). It could be interesting to observe collaboration between multiple parties in a specific project over time (Boland et al., 2007). Yet the practical limitations of collecting such rich data in this type of inter-organizational collaborations could be a point of attention.

Discussions with the focus group revealed that enactment of a collective affordance can be advanced or inhibited by differences in perceived collective benefits of using digital technology. Alternatively, the configurational-usage process can be partly determined based on a narrow perception of a collective goal. If collaborating actors retain inaccurate and narrow implicit affordances, digital technology may be used in counterproductive ways. Analyzing differences in perceptions of multiple actors regarding the same collective affordance may solve another piece of the digital-innovation puzzle.

\section{Conclusion}

This study improves understanding of the usage of pervasive digital technologies in digital innovation. Configurational usage of pervasive digital technology is a dynamic, complex, and multi-layered endeavor, which depends on a variety of affordance enactments that have effects at the individual and collective level. Through these enactments, benefits of technology are realized in markedly different ways. Based on configurational usage as an ongoing process, it is expected that BIM technology may become even more pervasive in dynamic and complex design practice as time goes by. This expectation supports calls for additional research on the usage and organization of digital technology as a core part of digital-innovation research (Nambisan et al., 2017; Yoo et al., 2012). Based on insights on digital-technology usage, we refine the conceptualization of configurational usage to enable improved understanding of core processes of digital innovation. We propose a refinement of the affordance concept, a relaxation of structural boundaries of innovation, and an explicit iterative multi-level focus. By applying these refinements in the study of organization and usage of digital technology, the potential of configurational usage of digital technology as a core concept of digital innovation can be unlocked.

\section{Acknowledgements}

The authors gratefully acknowledge funding from the European Commission's Seventh Framework Programme, under grant agreement CRE8TV.EU - 320203. The grant enabled this research but has had no direct influence on the conduct of the research, or on the preparation of the article. This includes the content of the article and the interpretation of the findings.

Earlier versions of this paper have been presented at 76th Academy of Management Annual Meeting (2016), 32 st EGOS Colloquium (2016), Organizing for Digital Innovation Workshop (2016) at Free University (VU) Amsterdam, and Cre8tv.eu project Conference (2016) in Manchester. We are grateful for the helpful comments provided by the participants in these events, as well as by two anonymous reviewers.

\section{References}

Azhar, S., 2011. Building information modeling (BIM): trends, benefits, risks, and challenges for the AEC industry. Leadersh. Manag. Eng. 11 (3), 241-252.

Barley, S.R., 1990. The alignment of technology and structure through roles and networks. Adm. Sci. Q. 35 (1), 61-103.

Becker, M., Lazaric, N., 2009. Organizational Routines: Advancing Empirical Research. Edward Elgar.

Benner, M.J., Tushman, M., 2002. Process management and technological innovation: a longitudinal study of the photography and paint industries. Adm. Sci. Q. 47 (4), 676-707.

Boland, R.J., Lyytinen, K., Yoo, Y., 2007. Wakes of innovation in project networks: the case of digital 3-D representations in architecture, engineering, and construction. Organ. Sci. 18 (4), 631-647.

Bryde, D., Broquetas, M., Volm, J.M., 2013. The project benefits of building information modelling (BIM). Int. J. Proj. Manag. 31 (7), 971-980.

Burton-Jones, A., Gallivan, M.J., 2007. Toward a deeper understanding of system usage in organizations. Mis Q. 31 (4), 657-679.

Burton-Jones, A., Straub, D.W., 2006. Reconceptualizing system usage: an approach and empirical test. Inf. Syst. Res. 17 (3), 228-246.

Chemero, A., 2003. An outline of a theory of affordances. Ecol. Psychol. 15 (2), 181-195.

DeSanctis, G., Poole, M.S., 1994. Capturing the complexity in advanced technology use: adaptive structuration theory. Organ. Sci. 5 (2), 121-147.

Dossick, C.S., Neff, G., 2009. Organizational divisions in BIM-enabled commercial construction. J. Constr. Eng. Manag. 136 (4), 459-467.

Eisenhardt, K.M., Graebner, M., 2007. Theory building from cases: opportunities and challenges. Acad. Manag. Rev. 50 (1), 25-32.

Ewenstein, B., Whyte, J., 2009. Knowledge practices in design: the role of visual representations as `Epistemic objects. Organ. Stud. 30 (1), 07-30.

Faraj, S., Azad, B., 2012. The materiality of technology: an affordance perspective. Mater. Organ.: Soc. Interact. Technol. World 237-258.

Feldman, M.S., Orlikowski, W.J., 2011. Theorizing practice and practicing theory. Organ. Sci. 22 (5), 1240-1253.

Felin, T., Foss, N.J., Heimeriks, K.H., Madsen, T.L., 2012. Microfoundations of routines and capabilities: individuals, processes, and structure. J. Manag. Stud. 49 (8), 1351-1374.

Gaskin, J., Berente, N., Lyytinen, K., Yoo, Y., 2014. Toward generalizable sociomaterial inquiry: a computational approach for zooming in and out of sociomaterial routines. Mis Q. 38 (3), 849-871.

Gerring, J., 2007. Case Study Research: Principles and Practices. Cambridge University Press, Cambridge, UK.

Gibson, J.J., 1977. The theory of affordances. In: Shaw, R., Bransford, J. (Eds.), Perceiving, Acting, and Knowing: Toward an Ecological Psychology: 67-82. Lawrence Erlbaum Associates, Hillsdale, NJ.

Henfridsson, O., Nandhakumar, J., Scarbrough, H., Panourgias, N., 2018. Recombination in the open-ended value landscape of digital innovation. Inf. Organ. 28 (2), 89-100.

Kane, G.C., Labianca, G., 2011. IS avoidance in health-care groups: a multilevel investigation. Inf. Syst. Res. 22 (3), 504-522.

Karsten, H., 2003. Constructing interdependencies with collaborative information technology. Comput. Support. Coop. Work. 12, 437-464.

Kozlowski, S.W.J., Klein, K.J., 2000. A multilevel approach to theory and research in organizations. In: Klein, K.J., Kozlowski, S.W.J. (Eds.), Multilevel Theory, Research and Methods in Organizations. Jossey-Bass, pp. 3-90.

Leonardi, P.M., 2011. When flexible routines meet flexible technologies: affordance, constraint, and the imbrication of human and material agencies. Mis Q. 35 (1), 147-167.

Leonardi, P.M., 2013. When does technology use enable network change in organizations? A comparative study of feature use and shared affordances. Mis Q. 37 (3), $749-775$.

Lobo, S., Whyte, J., 2017. Aligning and reconciling: building project capabilities for digital delivery. Res. Policy 46 (1), 93-107.

Markus, M.L., Silver, M.S., 2008. A foundation for the study of IT effects: a new look at DeSanctis and Poole's concepts of structural features and spirit. J. Assoc. Inf. Syst. 9 (10), 609-632. 
Nambisan, S., Lyytinen, K., Majchrzak, A., Song, M., 2017. Digital innovation management: reinventing innovation management research in a digital world. Mis Q. (1), 41.

Norman, D. A. (1988). The Psychology of Everyday Things. New York, Basic Books. Oborn, E., Barrett, M., \& Davidson, E. 2011. Unity in Diversity: Electronic Patient Record Use in Multidisciplinary Practice. Information Systems Research, 22(3), 547564.

Orlikowski, W.J., 2000. Using technology and constituting structures: a practice Lens for studying technology in organizations. Organ. Sci. 11 (4), 404-428.

Orlikowski, W.J., Iacono, C.S., 2001. Research commentary: desperately seeking "IT" in IT research - a call to theorizing the IT artifact. Inf. Syst. Res. 12 (2), 121-134.

Patton, M.Q., 2002. Qualitative Research and Evaluation Methods, 3rd ed. Thousand Oaks: Sage.

Pentland, B.T., Feldman, M.S., 2007. Narrative networks: patterns of technology and organization. Organ. Sci. 18 (5), 781-795.
Pols, A.J.K., 2012. Characterising affordances: the descriptions-of-affordances-model. Des. Stud. 33, 113-125.

Tsoukas, H., Chia, R., 2002. On organizational becoming: rethinking organizational change. Organ. Sci. 13 (5), 567-582.

Whyte, J., 2011. Managing digital coordination of design: emerging hybrid practices in an institutionalized project setting. Eng. Proj. Organ. J. 1 (3), 159.

Yin, R., 2011. Qualitative Research From Start to Finish. The Guilford Press.

Yoo, Y., Henfridsson, O., Lyytinen, K., 2010. The new organizing logic of digital innovation. Inf. Syst. Res. 21 (4), 724-735.

Yoo, Y., Boland, R.J., Lyytinen, K., Majchrzak, A., 2012. Organizing for innovation in the digitized world. Organ. Sci. 23 (5), 1398-1408.

Zammuto, R.F., Griffith, T.L., Majchrzak, A., Dougherty, D.J., Faraj, S., 2007. Information technology and the changing fabric of organization. Organ. Sci. 18 (5), 749-762. 